\title{
The effect of Saururus chinensis Baill against oxidative damage and inflammation
}

\author{
Dong Ryeol Hwang ${ }^{1 \#}$, Jin Boo Jeong ${ }^{1}$, Hyun Ji Eo ${ }^{1}$, Se Chul Hong ${ }^{2}$, \\ Ji Hyun $\mathrm{Yoo}^{2}$, Kun Hee Lee ${ }^{2}$, Bo Ram Kim², Jin Suk Koo ${ }^{1 *}$ \\ 1 : Medicinal Plant Resources Major, Andong National University, Andong,760749, Korea. \\ 2 : International Ginseng \& Herb Research Institute, Geumsan, 312-804, Korea.
}

\begin{abstract}
Objectives : ROS are involved in a wide spectrum of diseases including chronic inflammation and cancer. S.chinensis Baill, a perennial herb commonly called Chinese lizard's tail or Sam-baek-cho in Korea, is used for the treatment of edema and inflammatory diseases in the Oriental folk medicine. In this study, we investigated the antioxidant activities and anti-inflammatory effects of the two extracts, water(WE) and ethyl acetate(EAE) from S.chinensis Baill.

Methods : Anti-oxidant activity was evaluated using Fe2+ chelating and hydroxyl radical scavenging assay. DNA cleavage assay, and western blot and immunostaining for phospho-p65 were performed to evaluate anti-oxidative effect. Anti-inflammatory effect was performed using NO generation assay and western blot in LPS-stimulated RAW264.7 cell.

Results : In Fe2+ chelating activity and hydroxyl radical scavenging activity, WE showed more strong scavenging activity for hydroxyl radical than EAE. WE scavenged hydroxyl radical by $12 \%$ at $3.2 \mu \mathrm{g} / \mathrm{ml}, 21 \%$ at $16 \mu \mathrm{g} / \mathrm{ml}, 32 \%$ at $80 \mu \mathrm{g} / \mathrm{ml}, 66 \%$ at $400 \mu \mathrm{g} / \mathrm{ml}$ and $82 \%$ at $2000 \mu \mathrm{g} / \mathrm{ml}$, respectively. In addition, WE showed more strong chelating activity than EAE. WE chelated Fe2+ ion by $1.1 \%$ at $3.2 \mu \mathrm{g} / \mathrm{ml}, 8.2 \%$ at $16 \mu \mathrm{g} / \mathrm{ml}, 26.3 \%$ at $80 \mu \mathrm{g} / \mathrm{ml}, 72 \%$ at $400 \mu \mathrm{g} / \mathrm{ml}$ and $89 \%$ at $2000 \mu \mathrm{g} / \mathrm{ml}$, respectively. Also, WE inhibited oxidative damage via its anti-oxidant activity. In anti-inflammatory effect, EAE inhibited NO production and iNOS expression. In addition EAE suppressed the NF- $\kappa$ B and MAPK signaling pathway in LPS-stimulated RAW 264.7 cells.

Conclusions : Together, these data indicate that $S$. chinensis Baill, shows anti-oxidant activity and anti-inflammatory effect.
\end{abstract}

Key words : S. chinensis Baill, Reactive Oxygen Species, Oxidative DNA damage, Inflammation

\section{Introduction}

Oxidative stress is defined as an imbalance between production of free radicals and reactive metabolites, so-called oxidants or reactive oxygen species (ROS), and their elimination by protective mechanisms, referred to as antioxidants. This imbalance leads to damage of important biomolecules and cells, with potential impact on the whole organism ${ }^{1)}$. Under a sustained environmental stress, ROS are produced over a long time, and thus significant damage may occur to cell structure and functions and may induce somatic mutations and neoplastic transformation ${ }^{2,3)}$. Also, ROS are involved in a wide spectrum of diseases, including chronic inflammation ${ }^{4}$.

The mechanism for inflammation injury is attributed to release of ROS from activated macrophages. The over-production results in tissue injury by damaging macromolecules and lipid peroxidation of membranes ${ }^{5}$. Inaddition, ROS induces inflammation by stimulating release of mediator, nitric oxide(NO) which stimulates recruitment of additional macrophages. Thus free

\footnotetext{
* Corresponding author : Jin Suk Koo, Medicinal Plant Resources Major, Andong National University, Andong, Korea. 760749.

- Tel : +82548205464 · Fax: +82548206252 ·E-mail : kimkoo1114@andong.ac.kr

\# First author : Dong Ryeol Hwang, Medicinal Plant Resources Major, Andong National University, Andong, Korea. 760749.

- Tel : +82548205464 • E-mail : aaa1007aaa@nate.com

· 접수 : 2012년 9월 15일 · 수정 : 2012년 11월 3일 ·채택 : 2012년 11월 6일
} 
radicals are important mediators that provoke or sustainin flammatory processes and, consequently, their neutralization by antioxidants and radical scavengers can attenuate inflammation ${ }^{6)}$.

Most clinically important medicines are steroidal or non-steroidal anti-inflammatory chemical therapeutics for treatment of inflammation-related diseases. Though these have potent activity, long-term administration is required for treatment of chronic disease. Furthermore, these drugs have various and severe adverse effects. Therefore, naturally occurring agents, with high effectiveness and very few side-effects, are desirable as substitutes for chemical therapeutics ${ }^{7}$.

S. chinensis Baill, a perennial herb commonly called Chinese lizard' $\mathrm{s}$ tail or Sam-baek-cho in Korea, is used for the treatment of edema and inflammatory diseases in the Oriental folk medicine ${ }^{8)}$. In this study, we investigated whether $S$. chinensis Baill has anti-oxidative and anti-inflammatory properties in the non-cellular system and cellular system.

\section{Materials and Methods}

\section{Sample preparation}

S. chinensis Baill was kindly provided by Bonghwa Alpine Medicinal Plant Experiment Station, Korea. For water extracts (WE), One kilogram of $S$. chinensis Baill was extracted with $2 \mathrm{~L}$ distilled water with shaking for 24 hours. After 24 hours, the extract (123 g, yield rate: 12.3\%) was filtered and then freeze-dried. And for ethyl acetate extracts (EAE), one kilogram of $S$. chinensis Baill was extracted with 2L of $80 \%$ methanol with shaking for 24 hours. After 24 hours, extract with 80\% methanol was filtered, concentrated to approximately $400 \mathrm{ml}$ volume using by a vacuum evaporator, and fractioned with ethyl acetate in a separating funnel. The ethyl acetate fraction (35g, yield rate: 3.5\%) was separated from themixture and evaporated by a vacuum evaporator. Two extracts were kept at $-80^{\circ} \mathrm{C}$.

\section{2. $\mathrm{Fe}^{2+}-$ chelating activity assay}

The reaction mixtures $(800 \mu \ell)$ contained $15 \mu \ell$ of $\mathrm{FeCl}_{2}$ $(2 \mathrm{mM}), 150 \mu \mathrm{l}$ of varying concentrations of the extracts and $605 \mu l$ of distilled water. The mixtures were shaken vigorously and left at room temperature for $30 \mathrm{~min}$. After $30 \mathrm{~min}, 30 \mu \mathrm{l}$ of ferrozine ( $5 \mathrm{mM}$ in methanol) was added and mixed. The absorbance of the $\mathrm{Fe}^{2+}$-ferrozine complex was measured at $562 \mathrm{~nm}$. Fe ${ }^{2+}$-chelating activity was calculated from the log-dose inhibition curve. All determination was carried out in triplicate.

\section{Hydroxyl radical scavenging assay}

Hydroxyl radical scavenger ability was measured according to a literature procedure ${ }^{9)}$ with a few modifications. Hydroxyl radical was generated from $\mathrm{FeSO}_{4}$ and $\mathrm{H}_{2} \mathrm{O}_{2}$, and detected by their ability to hydroxylate salicylate. The reaction mixture $(800 \mu \mathrm{l})$ contained $250 \mu \mathrm{l}$ of $\mathrm{FeSO}_{4}(1.5 \mathrm{mM}), 175 \mu \mathrm{l}$ of $\mathrm{H}_{2} \mathrm{O}_{2}(6$ $\mathrm{mM}), 300 \mu \mathrm{l}$ of sodium salicylate $(20 \mathrm{mM})$ and varying concentrations of the extracts. After a reaction for 30 min at $37^{\circ} \mathrm{C}$, the absorbance of the hydroxylated salicylate complex was measured at $562 \mathrm{~nm}$. Hydroxyl radical scavenger ability was calculated from the log-dose inhibition curve. All determination was carried out in triplicate.

\section{4. $\varphi \mathrm{X}-174 \mathrm{RF}$ I plasmid DNA cleavage assay}

Conversion of the supercoiled form of plasmid DNA to the open-circular and further linear forms has been used as an index of DNA damage ${ }^{10)}$. Reaction mixtures (25 $\mu$ ) contained $5 \mu \ell$ of $\varphi \mathrm{X}-174 \mathrm{RF}$ I plasmid DNA, 10 $\mu \mathrm{l}$ of varying concentrations of the extracts, $5 \mu l$ of 1 $\mathrm{mM} \mathrm{FeSO}_{4}$ or/and $5 \mu$ of $1 \mathrm{mM}$ hydrogen peroxide and were incubated at $37{ }^{\circ} \mathrm{C}$ for $30 \mathrm{~min}$. After $30 \mathrm{~min}, 5 \mu \mathrm{l}$ of asolution containing $50 \%$ glycerol (v/v), $40 \mathrm{mM}$ EDTA and $0.05 \%$ bromophenol blue was added to stop the reaction and the reaction mixtures was electrophoresed on $1 \%$ agarose gel, and the DNA in the gel was visualized and photographed under ultraviolet light after ethidium bromide staining..

\section{Phospho-H2A.X staining}

NIH 3T3 cells $\left(5 \times 10^{4}\right)$ were cultured in 6-well plates for 24 hoursat $37^{\circ} \mathrm{C}$. After 24 hours, extracts was treated and then incubated for $30 \mathrm{~min}$ at $37^{\circ} \mathrm{C}$. After $30 \mathrm{~min}$, hydroxyl radical was treated and then the cells were incubated for 24 hours at $37^{\circ} \mathrm{C}$. After 20 hours, the cells were fixed with $2 \%$ formaldehyde for $30 \mathrm{~min}$ and then washed with $1 \times \mathrm{PBS}$ for $5 \mathrm{~min}$ three times. PBS with $10 \%$ fetal bovine serum (PBS/FBS) was then added to block non-specific binding for an hour. After washing, anti phospho-H2A.X polyclonal anti-body was diluted in $0.1 \%$ saponin/PBS/FBS solution at 1:500 dilutions for an hour, and then washed with $1 \times \mathrm{PBS}$ for $5 \mathrm{~min}$ three times. Subsequent antibody, Alexa-Flour 488 goat anti-rabbit IgG, and DAPI were used against phospho-H2A.X antibody and nuclei, respectively and the cells were incubated in the dark for an hour. Then, the cells were washed with $1 \times$ PBS and mounted with antifade mounting medium. Mounted slides were viewed under a fluorescence microscope 
using a $60 \times$ oil immersion objective. The excitation wavelengths for DAPI and phospho-H2A.X were $359 \mathrm{~nm}$ and $494 \mathrm{~nm}$, respectively

\section{Measurement of NO production}

RAW 264.7 cells, a mouse macrophage line, $\left(2 \times 10^{5}\right.$ cells/well $)$ in $10 \%$ FBS-DMEM without phenol red were seeded in a 6 -well plate for 24 hours at $37^{\circ} \mathrm{C}$. Cells were washed with $1 \times \mathrm{PBS}$, replaced with fresh media, and then treated with the varying concentrations of WAE for 1 hour. And then the cells were $\mathrm{cp}$-treated with LPS $(1 \mu \mathrm{g} / \mathrm{ml})$ for 24 hours at $37{ }^{\circ} \mathrm{C}$. After 24 hours, $200 \mu$ l of the medium were placed in a 96-well plate and an equal amount of Griess reagent (1\% sulfanilamide and $0.1 \%$ $\mathrm{N}-1$-(naphthyl) ethylenediamine-diHCl in $2.5 \% \mathrm{H}_{3} \mathrm{PO}_{4}$ ) was added. The plate was incubated for additional 5 min at the room temperature and then the absorbance was measured at $540 \mathrm{~nm}$ with a microplate reader. The amount of nitric oxide was calculated using sodium nitrite standard curve.

\section{Western blot}

The cell pellets were resuspended in lysis buffer (50 $\mathrm{mM}$ Tris-HCl pH 7.4, $150 \mathrm{mM} \mathrm{NaCl}, 1 \mathrm{mM}$ EDTA, 1 $\mathrm{mM}$ EGTA, $10 \mu \mathrm{g} / \mathrm{ml}$ aprotinin, $10 \mu \mathrm{g} / \mathrm{ml}$ leupeptin, 5 $\mathrm{mM}$ phenylmethylsulfonyl fluoride [PMSF], and $1 \mathrm{mM}$ DTT) containing $1 \%$ Triton $\mathrm{X}-100$ for $30 \mathrm{~min}$ at $4{ }^{\circ} \mathrm{C}$ and centrifuged to yield whole-cell lysates. The proteins $\left(\begin{array}{lll}50 & \mu \mathrm{g}\end{array}\right)$ were separated by sodium dodecyl sulfate polyacrylamide gel electrophoresis and thentransferred into PVDF membranes. The PVDF membranes were then blocked for non-specific binding in blocking buffer (5\% non-fat milk in $1 \times$ TBS solution containing $0.1 \%$ Tween-20) for 1 hour and then washed with $1 \times \mathrm{TBS}$ solution $(1 \times \mathrm{TBS} \quad 0.1 \%$ containing $0.1 \%$ Tween-20). Subsequently, the membranes were incubated with the primary antibodies at 1:1000 dilutions in antibody dilution buffer with gentle shaking at $4^{\circ} \mathrm{C}$ for 18 hours and then washed with $1 \times$ TBS. After washing, the membrane was incubated with Phototope-HRP Western Blot Detection System, Anti-rabbit IgG, HRP-linked Antibody as the secondary antibody at 1:1000 dilutions in antibody dilution buffer for 1 hour at the room temperature and then washed again. After washing, the membranes were treated with the detection agent (Amersham Biosciences) and immediately developed in Polaroidfilm.

\section{Statistical analysis}

Statistical analysis was performed with the Student' s unpaired t-test, with statistical significance set at *, $P<0.05$

\section{Results}

\section{Antioxidant activity of S.chinensisBaill}

Antioxidant activities of the two extracts, water extracts (WE) and ethyl acetate extracts (EAE) from $S$. chinensis Baill were evaluated by hydroxyl radical scavenging activity and $\mathrm{Fe}^{2+}$ chelating activity.

WE showed more strong scavenging activity than EAE (data not shown). WE scavenged hydroxyl radical by $12 \%$ at $3.2 \mu \mathrm{g} / \mathrm{ml}, 21 \%$ at $16 \mu \mathrm{g} / \mathrm{ml}, 32 \%$ at $80 \mu \mathrm{g}$ $/ \mathrm{ml}, 66 \%$ at $400 \mu \mathrm{g} / \mathrm{ml}$ and $82 \%$ at $2000 \mu \mathrm{g} / \mathrm{ml}$, respectively (Fig. 1A). In addition, WE showed more strong chelating activity than EAE (data not shown). WE chelated $\mathrm{Fe}^{2+}$ ion by $1.1 \%$ at $3.2 \mu \mathrm{g} / \mathrm{ml}, 8.2 \%$ at $16 \mu \mathrm{g} / \mathrm{ml}, 26.3 \%$ at $80 \mu \mathrm{g} / \mathrm{ml}, 72 \%$ at $400 \mu \mathrm{g} / \mathrm{ml}$ and $89 \%$ at $2000 \mu \mathrm{g} / \mathrm{ml}$, respectively (Fig. 1B). These results indicated that $S$. chinensis Baill has anti-oxidant activity
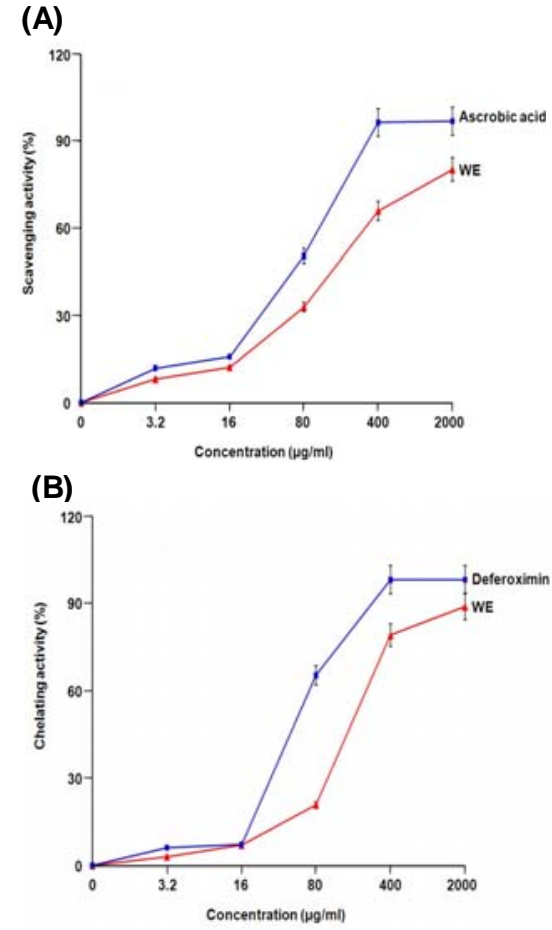

Fig. 1. $\mathrm{Fe}^{2+}$ chelating (A) and hydroxyl radical scavenging activity (B) of WE. The absorbance values were converted to scavengin $\mathrm{g}$ activity (\%) and the data plotted as the mean of replicate scavenging effects (\%) values $\pm 1 S . D . \quad(n=3)$ against extractc oncentration in $\mu \mathrm{g}$ extract per $\mathrm{ml}$ reaction volume.

2. Protective effect of $S$. chinensis Baill on oxidative DNA damage 
In non-cellular system, the plasmid DNA cleavage assay using phi X-174 RF I plasmid DNA was used as an initial approach toward determining whether $S$. chinensis Baill could protect DNA from oxidative damage induced by hydroxyl radical.

In phi X-174 RF I plasmid DNA, induction of single strand breaks to supercoiled double stranded plasmid DNA leads to formation of open circular DNA, while the formation of a linear form of DNA is indicative of double strand breaks. With this assay, WE showed the inhibitory effect against hydroxyl radical-induced oxidative DNA cleavage by $15 \%$ at 400 $\mu \mathrm{g} / \mathrm{ml}$ and $82 \%$ at $2000 \mu \mathrm{g} / \mathrm{ml}$ (Fig. 2A).

In cellular system using NIH 3T3 cells, protective effect of $S$. chinensis Baill against DNA damage induced by hydroxyl radical was evaluated by the phosphorylation level of H2A.X by western blot and immuno-staining. The phosphorylation of H2A.X increased in hydroxyl radical treated cells without WE. However, the treatment of WE decreased the expression of phospho-H2A. X by $47 \%$ at $80 \mu \mathrm{g} / \mathrm{ml}$, $53 \%$ at $400 \mu \mathrm{g} / \mathrm{ml}$ and $69 \%$ at $2000 \mu \mathrm{g} / \mathrm{ml}$ (Fig. 2B). This result was confirmed by changes of phospho-H2A.X foci into the nuclear in immuno-staining(Fig. 2C).

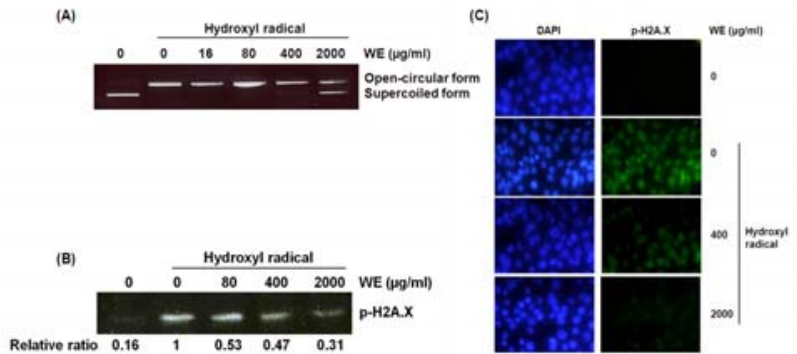

Fig. 2. Protective effect of WE from oxidative DNA damage by hydroxyl radical in non-cellular system $(A)$ and cellular system (B, C). phi X-174 RF I plasmid DNA was used for non-cellular DNA cleavage assay (A). In cellular system using $\mathrm{NIH}$ 3T3 cells, the cells was pre-treated with WE for $30 \mathrm{~min}$ and then co-treated with hydroxyl radical for 24 hours. Hydroxyl radical was generated from fenton reaction between $\mathrm{H}_{2} \mathrm{O}_{2}$ and $\mathrm{FeSO}_{4}$. Relative ratio was calculated by the ensity using the software Un-SCAN-IT gel Version 5.1 (Silk Scientific, Inc.). (C) Immuno-staining for phospho-H2AX

\section{Inhibitory effect of $\mathrm{S}$. chinensis Baill on} NO production and iNOS expression in LPS-stimulated RAW 264.7 cells

To determine whether EAE and WE inhibits LPS-induced NO production in RAW 264.7 cells, RAW 264.7 cells were pretreated with EAE or WE for 1 hour and then stimulated with LPS (1 $\mu \mathrm{g} / \mathrm{ml})$. After LPS stimulation for 24 hours, the cell medium was harvested, and the production of $\mathrm{NO}$ was measured using the Griess assay. In the present study, as shown in Fig. 3A, we found that EAE potently inhibited the production of $\mathrm{NO}$ in a dose-dependent manner. LPS treatment significantly increased NO production by $17.7 \mu \mathrm{M}$. However, EAE inhibited NO production. At the concentration $\mathrm{EAE}(50 \mu \mathrm{g} / \mathrm{ml})$, NO production was reduced to approximately basal levels compared with RAW 264.7 cells without LPS. But WE did not affect NO production (data not shown)

The over-production of NO is always associated with the up-regulation of iNOS protein. Therefore, to investigate whether the inhibitory effect of $\mathrm{EAE}$ on NO overproduction was mediated by down-regulating the expression of iNOS protein, western blot of iNOS protein was performed on the LPS-treated lysates with or without EAE. As shown in Fig. 3B, LPS treatment without EAE induced over-expression of iNOS protein. However, pre-treatment of EAE down-regulated the expression of iNOS protein in a dose-dependent manner. Especially, at the concentration of $50 \mu \mathrm{g} / \mathrm{ml}$, EAE completely suppressed iNOS expression.

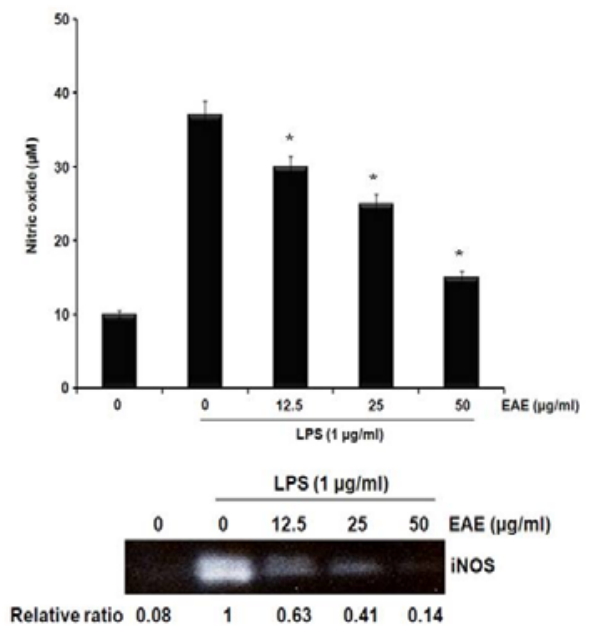

Fig. 3. Effect of EAE on LPS-induced NO production and iNOS expression in RAW264.7 cells. Cells were pre-treated with EAE for 1 hour and then $1 \mu \mathrm{g} / \mathrm{ml}$ of LPS was treated for 24 hours. The NO concentration in the medium was measured using Griess reagent. For SDS-PAGE/Western blot analysis, Cells were harvested and the re-suspended with lysis buffer. Fifty microgram protein was separated with $8 \%$ reducing sodium dodecyl sulfate polyacrylamide gel. Relative ratios in western blot were calculated by the density using the software Un-SCAN-IT gel Version 5.1 (Silk Scientific, Inc.)

\section{Inhibitory effect of $\mathrm{S}$. chinensis Baill on activation of $\mathrm{NF}-\kappa \mathrm{B}$ and MAPK signaling pathway}

To evaluate whether the inhibitory effect of EAE on iNOS expression is related to blocking $\mathrm{NF}-\kappa \mathrm{B}$ activation, we performed western blot for $\mathrm{I} \kappa \mathrm{B}-\alpha$ degradation and $\mathrm{I}_{\kappa} \mathrm{B}-\alpha$ phosphorylation, since the phosphorylation 
and subsequent degradation of $\mathrm{I} \kappa \mathrm{B}-\alpha$ is an essential step in $\mathrm{NF}-\kappa \mathrm{B}$ activation by various stimuli ${ }^{11)}$.

As shown in Fig. 4A, LPS induced Iк B- $\alpha$ degradation at 30 min after LPS stimulation. However, EAE dose-dependently suppressed Iк B- $\alpha$ degradation induced by LPS. Moreover, to determine whether the effect of $\mathrm{EAE}$ against Iк B- $\alpha$ degradation was mediated by blocking Iк $\mathrm{B}-\alpha$ phosphorylation, we evaluated the inhibitory effect of EAE against the phosphorylation of $\mathrm{I} \kappa \mathrm{B}-\alpha$ induced by LPS, and found that EAE significantly reduced $\mathrm{I} \kappa \mathrm{B}-\alpha$ phosphorylation. From these results, it is thought that $S$. chinensis Baill inhibits LPS-induced NF- $\mathrm{K}$ B activation.

To further investigate whether the inhibition of $\mathrm{EAE}$ on the expression of iNOS via blocking NF-kB activation is related to the modulation of MAPK pathway, we evaluated the effects of the EAE on phosphorylation of p38, ERK1/2 and JNK in LPS-stimulated RAW 264.7 cells by western blot (Fig. 4B). Hyper-phosphorylation of p38, ERK1/2 and JNK was observed in RAW264. 7 cells treated with LPS alone compared to the untreated cells. However, EAE suppressed LPS-induced phosphorylation of p38, ERK1/2 and JNK. These results suggest that $S$. chinensis Baill blocks the phosphorylation of p38, ERK1/2 and JNK to suppress the inflammatory response in LPS-stimulated RAW 264.7 cells.

Our data indicate that $S$. chinensis Baill possesses the anti-inflammatory effect through suppressing $\mathrm{NF}-\mathrm{K} \mathrm{B}$ and MAPK signaling pathway.

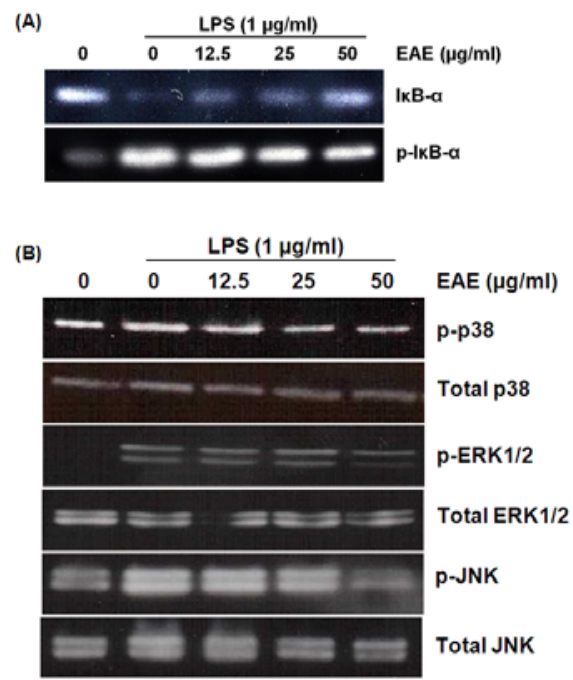

Fig. 4. Effect of EAE on LPS-induced activation of NF-K B (A) and MAPK (B) activation. Cells were pre-treated with EAE for 1 hour and then $1 \mu \mathrm{g} / \mathrm{ml}$ of LPS was treated for $15 \mathrm{~min}$. Cells were harvested and resuspended with lysis buffer. In SDS-PAGE/Western blot analysis, $50 \mu \mathrm{g}$ protein was separated with 15\% reducing sodium dodecyl sulfate polyacrylamide gel. Relative ratio in western blot was calculated by the density using the software Un-SCAN-IT gel Version 5.1 (Silk Scientific, Inc.).

\section{Discussion}

Hydroxyl radical scavenging is an important antioxidant activity because of very high reactivity of hydroxyl radical which enables it to react with a wide range of molecules found in living cells such as sugars, amino acids, lipids and nucleotides ${ }^{12)}$. In addition, Iron and copper are essential transition metal elements in the human body required for the activity of alarge range of enzymes and for some proteins involved in cellular respiration, $\mathrm{O}_{2}$ transport and redox reactions. Unfortunately, they contain unpaired electrons that enable them to participate in one-electron transfer reactions. Hence, they are powerful catalysts of autoxidation reactions ${ }^{13)}$. In this study, we found that WE from $S$. chinensis Baill scavenged hydroxyl radical and chelated $\mathrm{Fe}^{2+}$ ion. These results may suggest that $S$. chinensis Baill has strong anti-oxidant activities.

Oxidation is essential to many living organisms for the production of energy to fuel biological processes. However, oxygen-centered free radicals and other reactive oxygen species (ROS), which are continuously produced in vivo, result in cell death and tissue damage. These ROS induce various diseases such as cancer $^{2,3)}$. In this study, we found that WE from $S$. chinensis Baill protected DNA from oxidation induced by hydroxyl radical.

Anti-oxidant activity can be affected by two factors: (1) scavenging of radicals formed during reactions and (2) inhibiting the radical generation ${ }^{14)}$. The scavenging of hydroxyl radical by WE demonstrates its effectiveness against generated radicals. Moreover, the chelation of $\mathrm{Fe}^{2+}$ ion by WE demonstrates its effectiveness for inhibiting the radical generation. And it prevented oxidative DNA damage induced by hydroxyl radical in non-cellular system and cellular system.

ROS has been known to induce chronic inflammation ${ }^{4)}$. iNOS acts on L-arginine to produce NO, which is strongly associated with cytotoxicity and tissue damage and is involved in several processes such as inflammation and immunoregulation ${ }^{15)}$. In this study, we found that EAE from $S$. chinensis Baill the overproduction of NO via blocking iNOS expression in LPS-stimulated RAW 264.7 cells. These findings indicate that $S$. chinensis Baill has anti-inflammatory effect in mouse macrophage.

Pro-inflammatory mediators such as NO and iNOS is regulated by $\mathrm{NF}-\mathrm{K} B$ and MAPK signaling pathway. Therefore, the regulation of $\mathrm{NF}-\kappa \mathrm{B}$ and MAPK signaling pathway has been regarded as a major target for the prevention of chronic inflammation. In 
this study, we found that EAE from $S$. chinensis Baill in hibited $\mathrm{NF}-\kappa \mathrm{B}$ and MAPK signaling pathway. These findings indicate that $S$. chinensis Baill has anti-inflammatory effect through regulating $\mathrm{NF}-\kappa \mathrm{B}$ and MAPK signaling pathway.

\section{Conclusion}

In this study for evaluating antioxidant activities and anti-inflammatory effect of $S$. chinensis Baill, theresults were below:

1. WE from $S$. chinensis Baill scavenged hydroxyl radical and chelated $\mathrm{Fe}^{2+}$ ion.

2. WE from $S$, chinensis Baill protected DNA from oxidative damage induced by hydroxyl radical via its antioxidant activity

3. EAE from $S$. chinensis Baill inhibited NO production through blocking the overexpression of iNOS protein in LPS-stimulated RAW 264.7 cells

4. EAE from $S$. chinensis Baill inhibited activation of $\mathrm{NF}-\kappa \mathrm{B}$ and MAPK signaling pathway.

Together, this study indicates that $S$. chinensis Baill possesses the protective effect against the oxidative DNA damage and anti-inflammatory effect.

\section{Acknowledgement}

This work was supported by Basic Science Research Program through the National Research Foundation of Korea (NRF) funded by the Ministry of Education, Science and Technology (2011-0013786).

\section{References}

1. Durackova Z. Some current insights into oxidative stress. Physiol Res. 2010 ; 59 : 459-69.

2. Fang J, Seki T, Maeda H. Therapeutic strategies by modulating oxygen stress in cancer and inflammation. Adv Drug Deliv Rev. 2009 ; 61 : 290-302.

3. Khandrika L, Kimar B, Koul S, Maroni P, Koul HK. Oxidative stress in prostate cancer. Cancer Lett. 2009 ; 282 : 125-36.

4. Reuter S, Gupta SC, Chaturvedi MM, Aggarwal BB, Oxidative stress, inflammation, and cancer: How are they linked. Free Radic Biol Med. 2010 ; 11 : 1603-16.

5. Gutteridge JM. Lipid peroxidation and antioxidants as biomarkers of tissue damage. Clin Chem. 1995 ; 41 : 1819-28.

6. Geronikaki AA, Gavalas AM. Antioxidants and anti-inflammatory diseases: synthetic and natural antioxidants with anti-inflammatory activity. Com Chem High T Scr. 2006 ; 9 : 425-42.

7. Menichini F, Conforti F, Rigano D, Formisano C, Piozzi F, Senatore F. Phytochemical compositon, anti-inflammatory and antitumour activities of four Teucrium essential oils from Greece. Food Chem. 2009 ; 115 : 679-86.

8. Chung BS, Shin MG. Dictionary of Korean Folk Medicine. Seoul : Young Lim Sa. 1990 : 813-4.

9. Smirnoff N, Cumbes QJ. Hydroxyl radical scavenging activity of compatible solutes. Phytochemistry. $1989 ; 28: 1057-60$.

10. Jung Y, Surh Y. Oxidative DNA damage and cytotoxicity unduced by copper-stimulated redox cycling of salsolinol, a neurotoxic tetrahydroisoquinoline alkaloid. Free Radic Biol Med. 2001 ; 44 : 407-17.

11. Sung MJ, Davaatserem M, Kim W, Park SK, Kim SH, Hur HJ, Kin MS, Kim YS, Kwon DY. Vitisin A suppresses LPS-induced NO production by inhibiting ERK, p38, and $\mathrm{NF}-\mathrm{kB}$ activation in RAw 264.7 cells. Int Immunopharmacol. 2009 ; 9 : $319-23$.

12. Halliwell B, Gutteridge JMC. Biologically relevant metal ion-dependent $\mathrm{OH}$ generation. An update. FEBS Lett. 1992 ; 307 : 108.

13. Lloyd RV, Hanna PM, Mason RP. The origin of the hydroxyl radical oxygen in the Fenton reaction. Free Radic Biol Med. 1997 ; 22 : 885-8.

14. Leonard SS, Keil D, Mehlman T, Proper S, Shi X, Harris GK. Essiac Tea: Scavenging of reactive oxygen species and effects on DNA damage. J Ethnopharmacol. 2006 ; 103 : 288-96.

15. Bharat Reddy D, Reddanna P. Chebulagic acid (CA) attenuates LPS-induced inflammation by suppressing $\mathrm{NF}-\kappa \mathrm{B}$ and MAPK activation in RAw 264.7 macrophages. Biochem Biophys Res Commun. 2009 ; $381: 112-7$. 